\title{
Fuel Cell/Supercapacitor Passive Configuration Sizing Approach for vehicular applications
}

\author{
C. Dépature ${ }^{\mathrm{a}}$, A. Macías ${ }^{\mathrm{a}, \mathrm{c}}$, A. Jácome ${ }^{\mathrm{b}}$, L. Boulon $^{\mathrm{a}}$, J. Solano ${ }^{\mathrm{b}}$, João P. Trovão ${ }^{\mathrm{c}}$ \\ ${ }^{a}$ Université du Québec à Trois-Rivières, Hydrogen Research Institute, Trois-Rivières, Quebec, Canada \\ ${ }^{b}$ Universidad Industrial de Santander - Escuela de Ingenierías Eléctrica, Electrónica y de Telecomunicaciones, Bucaramanga, \\ Colombia \\ ${ }^{c}$ e-TESC Laboratory, Dept. Electrical \& Computer Engineering, University of Sherbrooke, Sherbrooke, Quebec, Canada
}

\begin{abstract}
Active configuration i.e., source coupling via a power converter, is the most common configuration for fuel cell/supercapacitor $(\mathrm{FC} / \mathrm{SC}$ ) vehicles. Passive connection of the $\mathrm{FC}$ with the SCs without any converters is an original and less expensive solution to distribute the power among the sources. This passive configuration does not require an energy management strategy. In fact, the power distribution only depends on the FC and SC impedance characteristics. Conventional methods to size the SC follow two criteria: storage capacity and maximum voltage. In this paper, a third criterion is added which is the FC operating current dynamics. This novel sizing methodology reduces the FC degradation and improves the global system efficiency. Experimental results provide validation to the proposed sizing approach. The SCs boost the FC to meet the requirements of the load with a guarantee of system stability reaching higher global performances and less stress to the FC.
\end{abstract}

Keywords: Energy management, Fuel cell, Passive configuration, Multi-source Sizing, Supercapacitor, Vehicular applications

\section{Introduction}

In the last decade, there has been a growing interest in fuel cell (FC) vehicles $[1,2]$. By using hydrogen $\left(\mathrm{H}_{2}\right)$, FC vehicles are considered as a promising solution to reduce greenhouse gases for long-range vehicles [3, 4]. However, FC systems offer a limited dynamic. Fast power transients can lead to a gas starvation, which can permanently damage the FC [5,6]. Furthermore, the energy flow of FC systems is unidirectional, which does not allow recovering braking energy. The literature review of energy storage systems (ESS) presented in [7], shows that the hybridization of ESSs with complementary features copes with the harsh working environment that a single ESS cannot achieve. Thus the coupling of FC with other ESS devices can improve the vehicle performances by handling the power transients, recovering braking energy, extending its lifetime and reducing its cost [8]. The hybrid configurations are classified in mainly in active and passive connection, based on the way that the components are connected to the DC bus [9]. Active configurations use at least one converter to combine the sources. Like the case of Toyota Mirai and Hyundai Tucson that have an active FC/battery configuration, using Ni-Mh and Li-Poly battery packs, respectively [10]. Honda has chosen an active fuel cell/supercapacitor (FC/SC) configuration to supply fast power dynamic of the vehicle in its 2002 FCX. However, the new 2014 FCX Clarity uses a FC/battery in active configuration. Active configurations require designing and performing a stable control associated to an energy management strategy and an additional DC/DC converter, where its size is a function of the power demand [11]. In [12], Blackwelder et al. proposed hybrid power source that allows the interconnection of a FC and a battery having dissimilar operating voltages, and supply high current peaks by an energy management strategy. In this respect, different criteria to design an energy management strategy can be found in the literature; minimization of fuel consumption or cost, and maximal efficiency, power identification or degradation [13, 14]. However, the converters utilized in the active configuration increase the energy losses, the volume, the weight, the cost and the failure probabilities of the hybrid system [15].

Contrary to active configuration, passive configurations avoid the use of power electronics converter. Passive configurations provide a natural power split by directly connecting the FC and an ESS in parallel. In such architecture, the current distribution between the FC and the ESS is not controlled. In this respect, a previous study explores an indirect power control in a FC/battery passive configuration by regulating the FC pressure [16]. However, this method operates the $\mathrm{FC}$ at pressure lower that its nominal value that makes complicated the purging. In [17], a comparative study shows that the passive configuration of $\mathrm{FC} / \mathrm{SC}$ reduce the hydrogen consumption due 
to the elimination of the energy conversion losses of the converter. In this regard, Arora et al. present that the hydrogen stoichiometry can be reduced for a passive configuration of $\mathrm{FC} / \mathrm{SC}$ to reduce the fuel overconsumption and avoid flooding inside the FC [18]. Another study shows that the passive hybridization of FC/SC improves the $\mathrm{FC}$ performance due to the SC removes the peaks from the demanded power [19]. Macias et al. compare the active and passive FC/SC configuration for a vehicular application [20]. Simulation results show that passive configuration increases the global efficiency due to the elimination of power electronics and makes the drawn power from the FC smoother that leads to longer lifetime of the FC. It should be noted that simulation has been used in the majority of studies and experimental validations considering driving operations are limited to a few studies [21, 22]. In another perspective, recent papers study the response of a passive $\mathrm{FC} / \mathrm{SC}$ configuration at the scale of each FC cell under different situations [23, 24]. The configuration of a FC with SC as energy/power buffer represents an interesting solution, because their high specific power and power density as compared to batteries, $\mathrm{SC}$ can assist a FC to meet the transients and high-power requirements peaks [25].

However, the parallel connection can result in a high inrush current if both systems do not have the same electric potential. Recently, some efforts have been made in the initial voltage conditions of the FC/SC passive configuration mainly focusing on the SC pre-charging and the passive system operation. In the commonly used $\mathrm{SCs}$, the terminals voltage decay can vary from 5 to $15 \%$ within $48 \mathrm{~h}$, due to auto-discharge phenomenon [26]. Therefore, in case that the SC is completely discharged or has a lower voltage than the FC in the startup phase of the passive hybrid energy system, the demanded load can produce a high inrush current and lead to the degradation of the FC system. Wu et al. use a pre-charging fixed resistor to charge the SC just below the FC open circuit voltage (OCV). This avoids inrush current at the time of connecting the sources but increases the startup time [22]. The instantaneous high input current can also be limited without a resistor, by controlling the initial $\mathrm{H}_{2}$ flow [27]. Silva et al. propose to turn on the FC after connecting the SC in order to increase progressively the voltage and reduce the high peak of current [28]. The presented principles are experimentally validated using a current pulse load. Silva et al. study FC/SC passive configuration by simulation and implement an experimental setup to study the effect of high current on FC degradation.

Another important aspect is the sizing of the hybrid system, i.e. the selection of the FC and ESS characteristics, this stage is crucial to obtain a functional passive power split. Compare to active configuration where a DC/DC converter adapts the voltage of the components to the bus voltage. In this respect, Arora et al. analyze the FC and $\mathrm{SC}$ characteristics to split the power based on the traction power frequency distribution, and concluded that the SC has to store enough energy to assist the FC [29]. In [30], a study of a passive SC/battery configuration presents a method to calculate the SC size by using a supercapacitor energy controller in a PV power smoothing application. This method determines the required energy storage size of the SC while assuring the defined smoothness of the battery power.

In view of the reviewed works, some efforts have already been made concerning the sizing of passive FC/SC configuration in vehicular applications. However, so far, these methods just consider the energetic behavior of the $\mathrm{SC}$ along the utilized profiles. In addition to common concerns regarding the voltage and SOC levels of the SC, the current dynamics operational limits of the FC are necessary to be considered along the different operation phases of the system. These requirements have made the formulation of this sizing method of a passive FC/SC hybrid energy system for a vehicle application. Prior to this paper, no sizing approach for FC vehicles considers the storage capacity, maximum voltage, and current dynamics of the FC at the same time. Experimental tests are performed to assess the performance of the proposed sizing approach. Three tests are carried out: SC pre-charging, load current step, and on-road operation. The remainder of the paper is organized as follows. Section II describes the studied FC/SC system along with the explanation of the model and the pre-charging strategy. Section III describes the FC and SC designs. Section IV copes with the real-time validation and the discussion of the experimental results.

\section{Vehicle modeling and representation}

\subsection{Studied vehicle}

The studied FC/SC architecture is based on the traction characteristics of low speed Nemo battery electric truck of the Hydrogen Research Institute of Université du Québec à Trois-Rivières (UQTR), shown in Fig. 1a. The studied traction subsystem is composed of a voltage-source inverter (VSI), a three-phase machine, a gearbox, a differential, and two driven wheels shown in Fig. 1b. The powertrain is built on an ACX-2043, $3 \phi$ AC/4.8 kW 
induction machine which is operated by an AC induction motor controller to set the motor speed. The speed and torque control of 3-phase AC motors has a wide input voltage range of $40 \mathrm{~V}$ to $80 \mathrm{~V}$. The main characteristics of the FC hybrid electric vehicle are detailed in [31]. The vehicle was instrumented with current and voltage sensors as well as a satellite global positioning system (GPS) antenna which provides speed and altitude information. An on-road urban driving cycle test has been carried out by the Nemo vehicle at the campus of the UQTR [32]. From this on-road test, the studied driving cycle is composed of a repetitive sequence of constant speed $(20 \mathrm{~km} / \mathrm{h})$, acceleration and braking phases. In addition, during this test, the vehicle has not been on a flat road. The maximum speed of Nemo is $40 \mathrm{~km} / \mathrm{h}$, and it reaches a maximum acceleration of $1.7 \mathrm{~m} / \mathrm{s}^{2}$.

a)

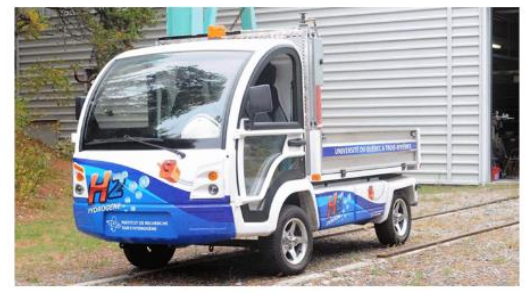

b)

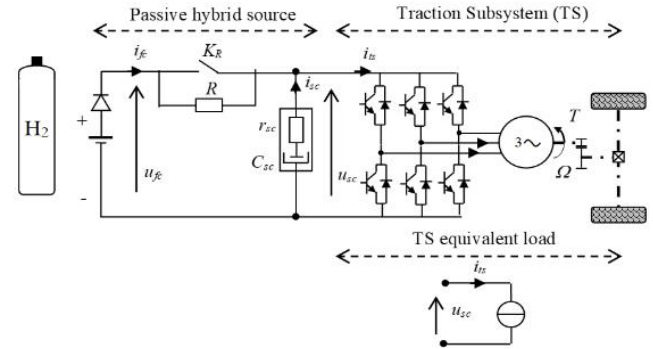

Fig. 1. Nemo electric vehicle, a) picture, b) studied FC/SC vehicle architecture

This results in a full-scale traction power profile $P_{t s}$ which is used as a reference for this paper in order to subject the sizing approach to the real operation of a specific vehicle shown in Fig. 2.

a)
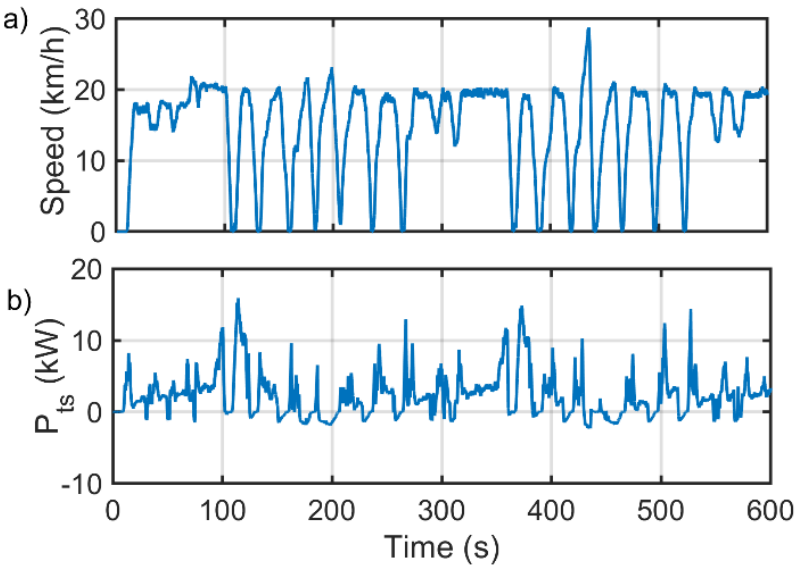

Fig. 2. Full-scale Nemo vehicle speed and power from an on-road test drive

In a pure electric mode with two passengers, the Nemo vehicle has an autonomy of $60 \mathrm{~km}$. This autonomy can be increased by replacing the original battery pack with a passive FC/SC energy system. Fig. $1 \mathrm{~b}$ shows the used passive configuration in which the FC is associated with a diode and the SC are directly connected in parallel. The traction is represented as an electric load connected to the DC bus voltage. As in a conventional capacitor, SC terminals voltage $\left(u_{s c}\right)$ depends on the energy stored in its electric field. When the SC are charged or discharged, the terminals voltage respectively increases or decreases in a rate which depends on the size of the SC. In this respect, the current in a SC can instantaneously change its value while the SC voltage can be considered continuous with a limited change rate. As the FC and the SC are connected in parallel, the voltage and the FC current are continuous and with a limited change rate which mainly depends on the SC capacitance. Depending on the SC characteristics, this configuration allows to filter the FC current $\left(i_{f c}\right)$, reducing stack faults, and degradation [33]. 
Fig. 3 illustrates the natural current distribution response of the utilized passive FC/SC energy system. The SC acts as a low-pass filter, that supply the requested current while the FC increase gradually its voltage. In this example, it is assumed that the FC and the SC starts at the same potential and the load current step maintains a constant value. This current step can be interpreted as the hardest load required to the FC/SC energy system, where the current is represented as per-unit (pu) current.

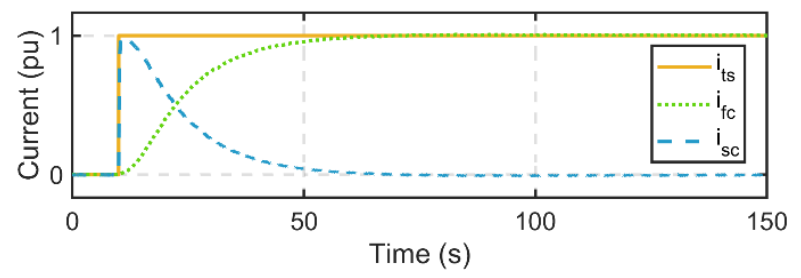

Fig. 3. FC/SC current distribution principle for a load current step.

When the passive system is turned on, the FC delivers a positive voltage. In this case, if the SC is initially discharged, a direct connection between the FC and the SC happens which is comparable to a short circuit of the FC resulting in a high peak inrush current $i_{f c}$. In [34], a study shows that the short circuit operation reduced the mass transfer performance that is reflected as a higher voltage drop at high current levels. To avoid this phenomenon a SC pre-charging system is implemented, as patented by NISSAN in 2005 [35]. The pre-charging system consists of a fixed resistor $R$ and a switch $K_{R}$, as shown in Fig. 1b. The current will flow through the resistor $R$ if the state of the switch $K_{R}$ is open. That means the resistor $R$ is placed in series with the FC and SC. The function of this resistor is to limit the inrush current during power-up phase, this high peak of current reduces the lifetime of the FC due to the starvation phenomena. This is the most classical method defined in the literature for DC bus capacitors initialization. When the voltage level of the FC is like the one of the SC, the state of the switch is changed to close. When the switch $K_{R}$ is close the resistor $R$ is bypassed, this means the current flows through the short-circuit generated by the contactor of the switch.

\subsection{Modeling}

The passive ESS is composed of a FC, a diode, a pre-charged resistor, a switch, and finally a SC pack. The FC operation depends on many phenomena such as the gas and liquid transport, heat exchanges, and electrochemical reactions. In this regard, there are two important approaches of mechanistic and semi-empirical modeling in FC domain. The former goes through these phenomena in details and the latter adopts a macroscopic approach to mask certain internal phenomena. Here, the FC model is represented in an energetic way as detailed in [36]. The $u_{f c}$ output voltage is then a non-linear function of the current $i_{f c}$, which depends on the double-layer and quasi-static capacity voltages of the cells [37]. The capacitive behavior of the cells changes in gas pressure (Nernst law), and electrical losses govern this function, which can be statically presented by a polarization curve [38]. In a passive configuration the current $i_{f c}$ imposed to the FC depends on the states of the switch $K_{R}$, the diode, and the pre-charged resistor as:

$$
\frac{u_{f c}-u_{s c}}{r_{D}+K_{R} R}=i_{f c}, \text { with } K_{R}=\{0,1\}
$$

where $r_{D}$ is the diode resistance, $R$ represents the pre-charged resistor, $u_{s c}$ is the SC voltage, and the state of the switch $K_{R}$ becomes 1 when it is open and the current flow through the resistor, and 0 when it is closed and precharging resistor is bypassed. As shown in Fig. 1b, the FC is connected in series with a diode to prevent reverse current into the FC and this circuit is connected in parallel with the SC. The diode represented as a resistor element causes a voltage drop, triggering a current flow from the FC to the system. This difference is the one that regulates the current of the FC.

The FC/SC electric parallel connection distributes the power of the FC and SC subsystems to the traction system load. The FC and traction subsystem current, $i_{f c}$ and $i_{t s}$, are added together to generate the SC currents $i_{s c}$, which is modeled by the Kirchhoff's current law (2).

$$
i_{s c}=i_{t s}-i_{f c}
$$

Regarding the SCs, a series $R C$ model is used to only consider their fast dynamics (3). The resistor $r_{s c}$ models the voltage drops during the charging and discharging phases, and the constant capacitance $C_{s c}$ characterizes the capacitive behavior of the SC. The linear dependence of the capacitance with respect to the voltage across the 
capacitor $u_{s c}$, the leakage resistance which induces losses when the SCs are not used, and the charge distributions phenomenon are not taken into account due to the fact that their time constants are very large compared with the dynamics of the considered application (from a few hundreds of seconds to several hours) [39].

$$
u_{s c}=r_{s c} i_{s c}+\frac{1}{C_{s c}} \int i_{s c} d t
$$

The traction subsystem is considered as an electric load (Fig. 1b). The current of traction subsystem, $i_{t s}$, is then expressed by the electrical traction power, $P_{t s}$ (depending on the considered driving cycle) and the DC bus voltage, $u_{s c}$ (see Fig. 2):

$i_{t s}=P_{t s} / u_{s c}$

\subsection{Energetic Macroscopic Representation and Pre-Charged Strategy}

The Energetic Macroscopic Representation (EMR) of the studied vehicle is deduced from the relationships presented in section 2.2 (Fig. 4). The components are connected respecting the physical interaction principle of action-reaction [40]. One of the main advantages of this graphical description is to represent the interaction of different physical phenomena in the same diagram.

The FC system, the SC, and the traction system are considered as electrical sources which impose the FC voltage $u_{f c}$, the SC voltage $u_{s c}$, and the traction subsystem current $i_{t s}$, respectively. The diode, the pre-charged resistor, and the switch are considered as a mono-domain conversion element with the voltages of $u_{f c}$ and $u_{s c}$ as the inputs, the current $i_{f c}$ as the output, and the reference switch state $K_{R}$ as the tuning input. The parallel connection is represented as a coupling element.

A strategy-level output needs to be defined, which will be the pre-charging strategy block of Fig. 4 . The precharged switch $K_{R}$ state depends on the SC voltage $u_{s c} . K_{R}$ is switched on when the SC voltage $u_{s c}$ reaches a value close to the FC OCV by the pre-charging strategy.

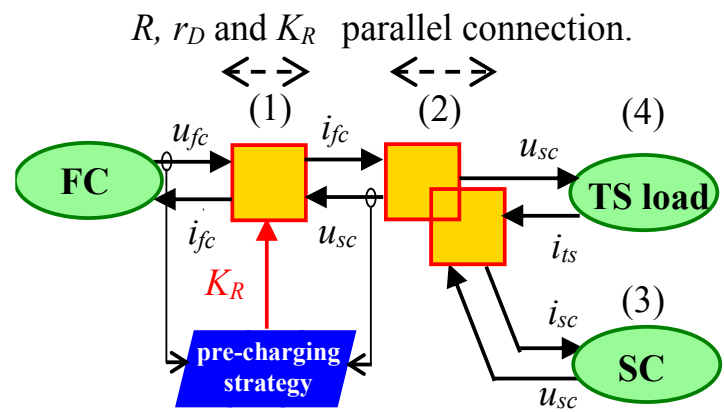

Fig. 4. Energetic Macroscopic Representation of the studied vehicle

\section{Fuel Cell and Supercapacitor Design}

\subsection{Hybrid System Design}

In this paper, the studied hybrid power source is based on a Horizon 500-W FC (H-500 FC). The rated power of the selected FC can supply the requested power of the $1 / 25^{\text {th }}$ scale electrical traction power during the maximum speed and high acceleration rates. In order to preserve and reduce the FC degradation, frequency decomposition of traction power is often performed for active $\mathrm{FC} / \mathrm{SC}$ configurations with power electronics [41, 42]. If the system is well designed, the passive coupling of the FC with SC naturally preserves the FC from excessively fast dynamic power demands. If the FC is expose to sudden peak currents, its lifetime is reduced, and the output voltage will not get a steady value at the requested moment. This effect is due to the phenomenon of starvation, which means there is an insufficient supply of reactant gas [43]. Thus, to avoid starvation some authors considered that the power gradient value should be between $2 \%$ to $20 \%$ of the FC maximum power per second, or 4 to $50 \mathrm{~A} / \mathrm{s}$ as the $\mathrm{FC}$ 
dynamic limitation [44]. In addition, other studies indicate that the FC suffers a percentage of power reduction when there is a load variation rate higher than $10 \%$ of the maximum FC power per second $[45,46]$. These limitations generally result in a current slope which should not be exceeded in order to reduce the stress in the FC system. Considering typical values on the literature, it has been assumed that a limitation of $2 \mathrm{~A} / \mathrm{s}$ allows to avoid degradation and gas starvation. That means the system can reach its maximum current in $15 \mathrm{~s}$, while respecting the slow dynamics of the FC.

In order to select the adequate value, a comparison of several cut-off frequencies responses to a step traction current is shown in Fig. 5. In the figure the FC current is plotted in per-unit, and the maximum corresponding current slope is also indicated. Assuming a current step of $30 \mathrm{~A}$, which correspond to the nominal current of the Horizon $\mathrm{FC}$, the maximum current slope varies from $18.9 \mathrm{~A} / \mathrm{s}$ for a cut-off frequency of $100 \mathrm{mHz}$ to $1.8 \mathrm{~A} / \mathrm{s}$ for a cut-off frequency of $10 \mathrm{mHz}$. The selected cut-off frequency is $f_{c}=10 \mathrm{mHz}$, which corresponds to a maximum current slope of $1.8 \mathrm{~A} / \mathrm{s}$. The resulted current slope respects the specified current limitation of $2 \mathrm{~A} / \mathrm{s}$. However, the selected cutoff frequency has a stabilization time of about $80 \mathrm{~s}$ as shown in Fig. 5. Operating at this frequency has two main advantages. First, the FC does not suffer from any significant current transients $(1.8 \mathrm{~A} / \mathrm{s})$, preventing it from gas starvation and its degradation effects [47]. Secondly, the FC rarely operates at its OCV since the stabilization time is very short. A frequency of $10 \mathrm{mHz}$ therefore preserves the FC membrane and catalyst, since operation at the OCV accelerates the generation of peroxide and hydroperoxide radicals, which attack the membrane and catalyst $[48,49]$. Finally, if the FC and the SC have the same initial potential, the startup time to achieve $50 \%$ of the rated current for the FC system is 10 seconds. Regarding the United States Department of Energy (DOE) targets for light-duty FC vehicles, the ultimate target for FC startup time to full-flow is between 5 to $15 \mathrm{~s}$, depending on the ambient temperature [50]. The chosen cut-off frequency of $10 \mathrm{mHz}$ is thus a compromise between performance and degradation minimization. However, the SC sizing should be done taking into consideration the maximum current peak of the system that corresponds to maximum acceleration.

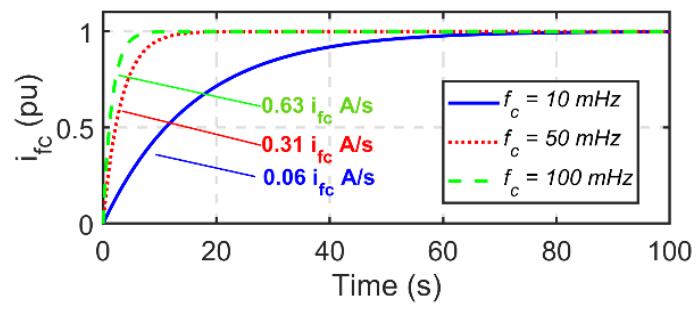

Fig. 5. Frequency decomposition and current slopes considering a traction current step

\subsection{Supercapacitor Design}

By comparison, FC/SC passive configurations are less expensive and simpler to operate than active configurations, nevertheless, the performance depends on the sizing of the energy systems [51]. Conventional methods size SC according to two criteria: storage capacity and maximum voltage [22, 29, 33, 51]. However, in this work, a third criterion has been added which is the current dynamic range of the FC. This section first explains the two common criteria found in the literature, then how SC parameters affect the FC operating frequency, and finally based on the desired FC current dynamic this analysis is used to size the SC

Concerning the storage capacity criterion, the SC must assist the FC regardless of the load stress imposed by the traction. In this respect, $\mathrm{SC}$ need to be designed according to their storage capacity $(\mathrm{Wh})$ since their energy density is relatively low $(5-10 \mathrm{Wh} / \mathrm{kg})$ compared to their power density $(1-5 \mathrm{~kW} / \mathrm{kg})$ [52]. Hence, if the energy requirements are met, the power requirements will be met too. This requires knowing the maximal vehicle operation requirements by a frequency decomposition. The frequency decomposition at $10 \mathrm{mHz}$ of the $1 / 25^{\text {th }}$ scale electrical traction power during the road test of Fig. 2b, is divided in low frequency and compensation power. The low frequency power $\left(P_{L F}\right)$ is the power expected to be delivered by the FC, and the compensation power is the power that should be supplied by the SC. In order to identify the maximum requested energy during the driving cycle the compensation power component is integrated through the time and represented in terms of energy in the Fig. 6. From this analysis, the energy that SC needs to store is less than $1.05 \mathrm{Wh}$. 


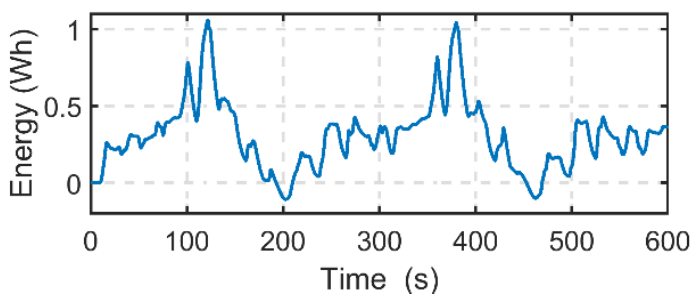

Fig. 6 compensation power in terms of energy evolution

Regarding the maximum voltage criterion, the maximum voltage of the SC must be higher than the FC's OCV. As the FC and diode are connected in parallel to the SC, the two circuits share the same voltage. For safety purposes, SC should not be overloaded. The right size of the SC arrangement avoids exceeding their maximum permissible voltage $[22,53]$. Apropos the third criteria, a signal flow graphs, and Mason's gain formula are useful to complex system analysis. In this paper, these methods are used to analyze the passive hybrid design. Mason's gain formula allows defining the transfer function of a complex system in an efficient way. It is often applied from signal flow graphs [54]. A signal flow graph consists of a diagram composed of a set of nodes connected by paths, representing a set of linear equations.

In the literature semi-empirical models are utilized to describe the behavior of the $\mathrm{FC}$, which is represented in a graphical way as the polarization curve [55]. Fig. 7 presents the H-500 FC static model experimentally validated. The FC polarization curve is composed of the reversible voltage; which is the maximum possible voltage of the FC, and irreversible voltage losses; which are the activation, ohmic and concentration losses. The activation loss represents the energy needed to start the reaction. The ohmic losses are caused by ionic, electronic, and contact resistances, which in most of the models is assumed as a linear function. The concentration losses happen at high currents and represents the mass transport, which is caused by the concentration reduction of hydrogen and oxygen gases in electrodes. In this work it is assume that the FC will operate mostly in the ohmic region. Therefore, the proposed SC design method assumes that the used models are linear. If the FC does not operate at OCV and high currents, this polarization curve can be linearized to provide the linear model of the studied FC:

$$
u_{f c}=u_{f c 0}-k i_{f c}
$$

where the linear FC OCV $\left(u_{f c 0}\right)$ is $28.61 \mathrm{~V}$ and $k=0.39$ is a linear coefficient.

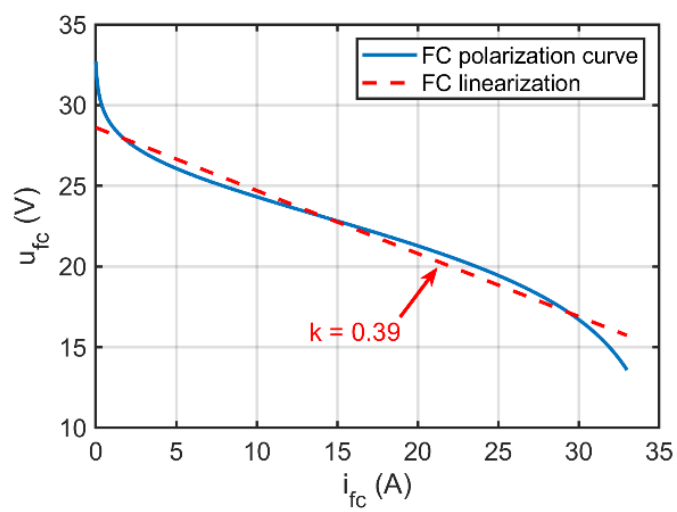

Fig. 7. H-500 FC polarization curve

The FC current $i_{f c}$ versus the traction system current $i_{t s}$ signal flow chart is presented in Fig. 8a. It has been obtained by using the model equations presented in section II.B, assuming a Laplace domain representation and the FC linear model.

The Mason's gain formula determines the linear transfer function $T(s)$ between an independent input (the traction system current $i_{t s}$ ) and a dependent output (the FC current $i_{f c}$ ) as follows:

$$
T(s)=\frac{\sum_{n} P_{n} \Delta_{n}}{\Delta}
$$


where $P_{n}$ is the $n$th path gain of the input variable to the output variable, $\Delta$ is the determinant of the graph, and $\Delta_{n}$ is the $P_{n}$ path cofactor. The determinant $\Delta$ is calculated as follows:

$\Delta=1-\sum_{o} L_{o}+\sum_{m, q} L_{m} L_{q}-\sum_{r, s, t} L_{r} L_{s} L_{t}+\cdots$

where $\sum L_{o}$ is the sum of all individual loop gains.
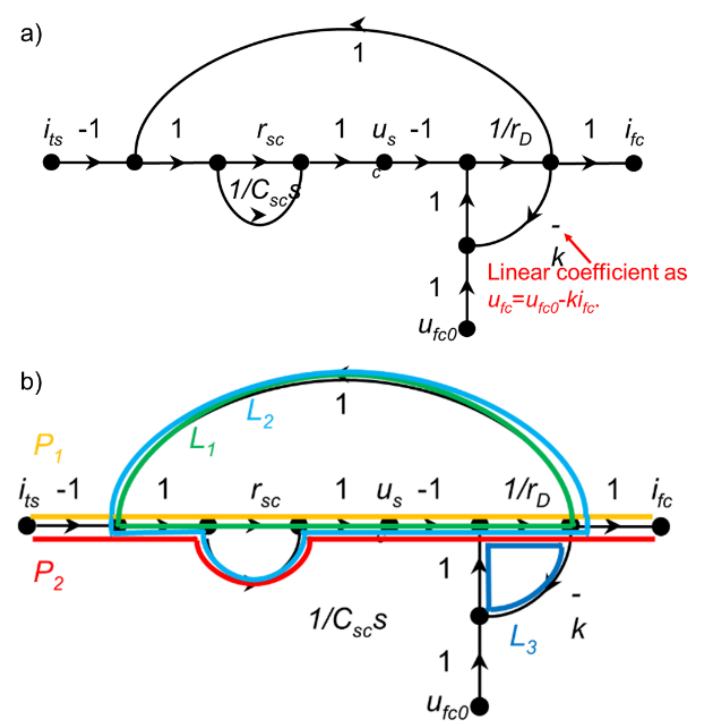

Fig. 8. Fuel cell current $i_{f c}$ versus traction system current $i_{t s}$, a) signal flow graph, b) Mason's gain formula application.

From the signal flow graph described in Fig. 8a, there are two forward paths $P_{1}$ and $P_{2}$ that link $i_{t s}$ to $i_{f c}$ (yellow and red paths presented in Fig. 8b, respectively) and 3 loops $L_{1}, L_{2}$ and $L_{3}$ (green, light blue and dark blue paths in Fig. 8b). Note that $P_{1}$ and $P_{2}$ touch all the loops so $\Delta_{1}=1$ and $\Delta_{2}=1 . L_{1}, L_{2}$ and $L_{3}$ touch each other leading to $\Delta_{1}=1$ $L_{1}-L_{2}-L_{3}(8) . T(s)$ is finally defined in (9).

$$
\begin{gathered}
\left\{\begin{array}{ccc}
P_{1}=\frac{R}{r_{D}} & L_{1}=\frac{R}{r_{D}} & \Delta_{1}=1 \\
P_{2}=\frac{1}{C r_{D} s} & L_{2}=\frac{1}{C r_{D} s} & \Delta_{2}=1 \\
& L_{1}=\frac{k}{r_{D}} & \Delta=1-L_{1}-L_{2}-L_{3}
\end{array}\right. \\
T(s)=\frac{i_{f c}}{i_{t s}}=\frac{P_{1} \Delta_{1}+P_{2} \Delta_{2}}{\Delta}=\frac{1+R C_{s}}{1+C\left(r_{D}+R+k\right) s}
\end{gathered}
$$

The stabilization of the obtained $T(s)$ is studied in the complex plane as shown in Fig. 9. The pole, represented by a cross, is the root of the denominator of $T(s)$. The zero, represented as a circle, is the root of the numerator. The system is exponentially stable since the pole is in the left half of the complex plane. It is also possible to compare $T(s)$ with the second order transfer function $T_{2 d}(s)$ :

$T_{2 d}(s)=\frac{\omega_{n}^{2}}{s^{2}+2 \xi \omega_{n} s+\omega_{n}^{2}}$

where $\xi$ represents the damping coefficient and $\omega_{n}$ the natural pulsation of the second order system. Considering that $T(s)$ and $T_{2 d}(s)$ poles have the same real values (red dashes in Fig. 9) and assuming that the zero of $1 / C_{s c} r_{s c}$ is higher than the pole of $1 / C_{s c}\left(r_{D}+r_{s c}+k\right)$, it is possible to identify that:

$\xi \omega_{n}=\frac{1}{C_{s c}\left(r_{D}+r_{s c}+k\right)}$ 
with $\xi=1$ (see the green part in Fig. 9), and $\omega_{n} t_{s}=4.744$ from the settling time chart. The FC current stabilization time at $1 \%$ of the final value in steady state $t_{s}$ can be defined as:

$t_{s}(1 \%)=4.744 C_{s c}\left(r_{D}+r_{s c}+k\right)=5 \tau$

where $\tau$ is the time constant of the FC operation. Finally, the FC current cut-off frequency can be calculated as:

$f_{c}=\frac{1}{2 \pi \tau}=\frac{5}{2 \pi t_{S}(1 \%)}=\frac{5}{2 \pi 4.744 C_{s c}\left(r_{D}+r_{s c}+k\right)}$

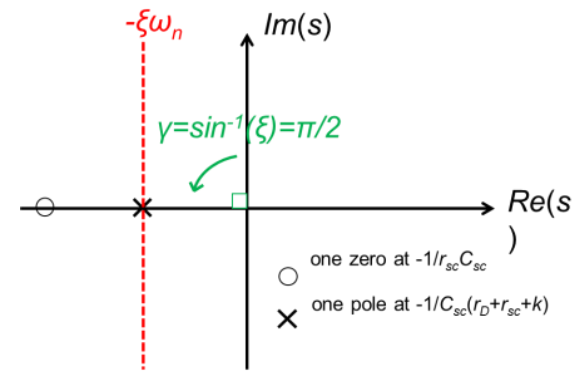

Fig. 9. Complex plan of the studied transfer function $T(s)$

\subsection{Study case}

Based on the three criteria of the proposed sizing method the standard electrolytic capacitor value that satisfy the constrains is a pack of two 16.2 V-58F SC (BMOD0058 Maxwell SC) connected in series. This arrangement has a higher voltage than the H-500 FC OCV, enough energy to assist the FC, and a cut-off frequency of $13 \mathrm{mHz}$. The main characteristic of the FC/SC testbench are summarized in Table 2. The useful energy of the 2 SC Maxwell modules $E_{u}$ is computed from the nominal voltage $u_{s c 0}$ up to the $50 \%$ of maximum voltage by (14), which is sufficient to operate in a good efficiency operation range and to avoid physical instability due to a low FC voltage $[53,56]$.

$E_{u}=\frac{1}{2} C_{s c} u_{s c 0}^{2}\left(1-\left(\frac{50}{100}\right)^{2}\right)=11360 J \frac{1 h}{3600 s}=3.15 W h$

As the SCs have been selected according to the FC desired operating current dynamic and the FC OCV, it is not surprising that the SCs seem energetically oversized (3.15Wh compared to the $1.05 \mathrm{Wh}$ required). The energy supplied by the SC do not exceed its limits, this ensures the physical stability and high SC efficiency.

\begin{tabular}{ccc|}
\multicolumn{3}{c}{ Table 2 - Reduced-scale FC/SC passive vehicle } \\
Component & Variable & Value \\
\hline & $u_{f c}$ & $15-32 \mathrm{~V}$ \\
Fuel Cell & $P_{f c, \max }$ & $500 \mathrm{~W}$ \\
& $u_{f c 0}$ & $28.6 \mathrm{~V}$ \\
& $k$ & 0.39 \\
Supercapacitors & $u_{s c 0}$ & $32.4 \mathrm{~V}$ \\
& $C_{s c}$ & $29 \mathrm{~F}$ \\
Diode & $r_{s c}$ & $44 \mathrm{~m} \Omega$ \\
Pre-charge resistor & $r_{D}$ & $2 \mathrm{~m} \Omega$ \\
Power load & $R$ & $1 \Omega$ \\
& $P_{\text {load, } \max }$ & $1.2 \mathrm{~kW}$ \\
\hline
\end{tabular}




\section{Real-Time Validation}

\subsection{Experimental Setup}

Based on the traction characteristics of the low speed Nemo (Fig. 1a), a reduced scale validation is performed on an experimental platform as shown in Fig. 10. The set-up is composed of a 500-W Horizon PEM FC, a pack of 2 Maxwell SCs, a diode, a $1 \Omega$ pre-charged resistor and a $1.2 \mathrm{~kW}$ programmable DC load to emulate the traction subsystem. The programmable DC load is used as a load drive with a power reduction of 25 compared to the fullscale studied vehicle. For the validation purpose, only mechanical braking is considered. Furthermore, the components with the selected sizes are cable of supplying the requested power during a constant phase of maximum speed. Voltages and currents are measured with classical LEM transducers and voltage probes. As shown in Fig. 10a electric diagram of the testbench is composed of the FC system, the pre-charged resistor, the SC system, and the programmable load. These components are connected together by means of four 40 A contactors $K_{f c}, K_{R}, K_{s c}$ and $K_{\text {load. }}$. The contactor $K_{f c}$, and $K_{\text {load }}$ are implemented as safe contactors to stop the test in case of a failure.

a)

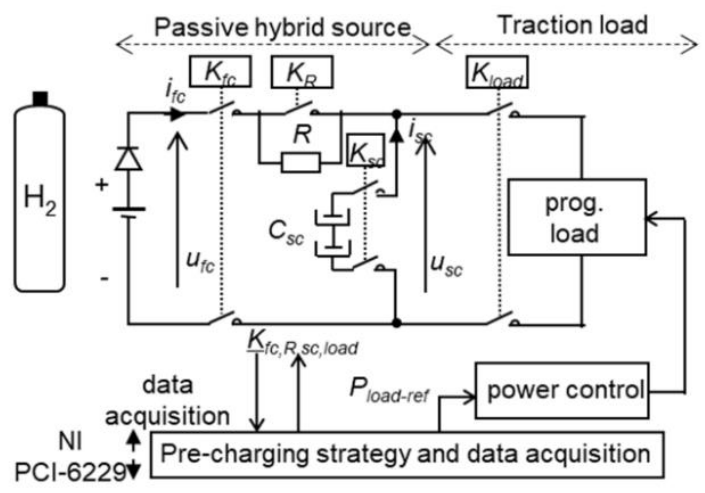

b)

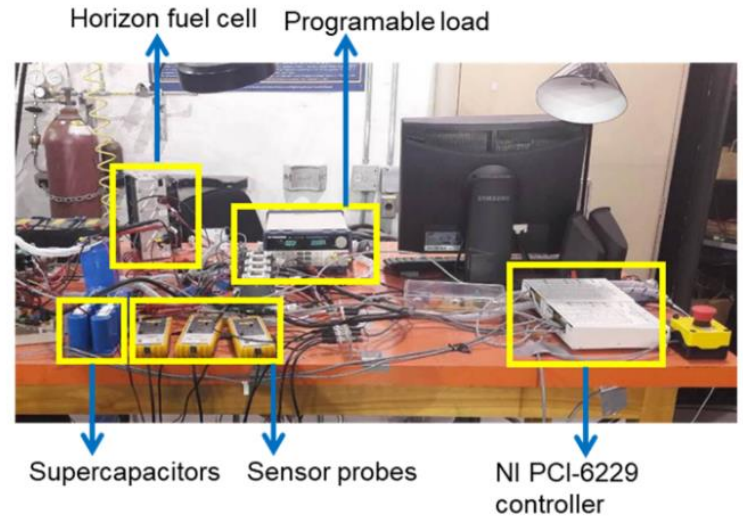

Fig. 10. Test bench, a) diagram, b) experimental platform

A test is proposed to validate the design of the FC/SC passive configuration system under the conditions of the maximum FC current. Fig. 11 shows the response of the system alongside a $30 \mathrm{~A}$ step current. When $t=0 \mathrm{~s}$, the values of $u_{f c}$ and $u_{s c}$ are $29.7 \mathrm{~V}$ and $29.3 \mathrm{~V}$, respectively. The voltage difference is linked to the voltage drop in the diode, and so the SCs are correctly loaded. A pulse current step $\left(i_{t s}=0-30 \mathrm{~A}\right)$ at $t=10 \mathrm{~s}$ is imposed on the passive $\mathrm{FC} / \mathrm{SC}$ system. From the proposed method, the objective FC operating frequency is $10 \mathrm{mHz}$. However, the SC sizes are limited in commercial standard values. Consequently, the FC current $i_{f c}$ has a stabilization time of $74 \mathrm{~s}$, which corresponds to an operating frequency of $13 \mathrm{mHz}$. The results show that the $\mathrm{SC}$ responds correspond to the calculated theoretical cut-off frequency of (13), although the FC polarization curve has been defined as a linear model. Indeed, the polarization curve characterization assumes voltage, current, and temperature steady state, thus neglecting the transient states. During this test, the minimum voltage of the $\mathrm{SC}$ is $18.8 \mathrm{~V}$. This voltage is higher than $u_{s c 0} / 2$. Consequently, the selected SCs allow to maintain an enough SC state of charge, which limits the currents and the efficiency of the SC. Finally, the configuration allows the system to respond to the traction demands in a passive way. Peak power demands are provided by the SC and the FC provides an average traction power. For example, the $440 \mathrm{~W}$ power demand at $t=10 \mathrm{~s}$ is exclusively provided by the $\mathrm{SC}$. The $\mathrm{FC}$ then progressively increase 
its power component and takeover of the SC contribution.

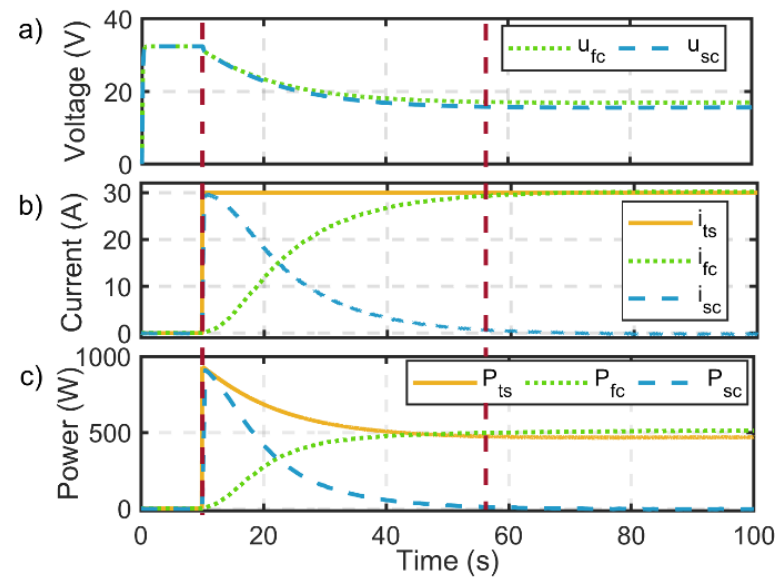

Fig. 11. Passive hybrid source current step validation, a) voltage profile, b) current profile, and c) power profile

\subsection{Supercapacitors Pre-Charging}

The developed pre-charging strategy is built and implemented in a National Instrument NI PCI-6229 controller. The management of the contactors allows two operation modes:

1) Mode 1: SC pre-charging. $K_{f c}$ and $K_{s c}$ are closed. $K_{R}$ and $K_{\text {load }}$ are opened. The system becomes a closed circuit with the FC, diode, pre-charging resistor and $\mathrm{SC}$ connected in series. The FC charges the SC up to its OCV. And the pre-charged resistor limits the inrush current $i_{f c}$.

2) Mode 2: Vehicle operation. $K_{f c}, K_{s c}, K_{R}$ and $K_{\text {load }}$ are closed. The emulated traction load is connected in parallel to the $\mathrm{SC}$ of the system. Therefore, the system becomes a circuit with three branches in parallels: the FC and the diode, the SC, and the load. The FC operation frequency depends on the SC characteristics.

The first pre-charging step is necessary to balance the $\mathrm{FC}$ and the $\mathrm{SC}$ at the same electric potential, this process is shown in Fig. 12. When the FC is turned on, it is on OCV. Then the FC is connected to the SC by closing the contactor $K_{f c}$ and $K_{s c}$ at $t=10 \mathrm{~s}$, its voltage drops instantly to around $20 \mathrm{~V}$. The pre-charged resistor limits the load current to $20 \mathrm{~A}$. The charging current decreases with a time constant about $38 \mathrm{~s}$, and then an operating frequency of $4.2 \mathrm{mHz}$. This corresponds to the frequency defined by Eq. (13), but considering the additional fixed pre-charged resistor of $1 \Omega$. The stabilization time is about $190 \mathrm{~s}$. The advantage of the chosen pre-charging method is that it limits the charging current, which avoids component stress during the FC/SC passive connection, however the SC charging time is relatively long. Note that for this pre-charging test, the SC was fully discharged. This is the worst operation case that should not happen often because the SC self-discharge time constant is relatively long [26]. More advanced pre-charging strategies could be used in further studies, including short-circuit or progressive FC/SC connection [28], using a Voltage Stabilization System (VSS) [57], or a control system to regulate the connection of a pre-charging resistance before starting the vehicle [58]. 
a)

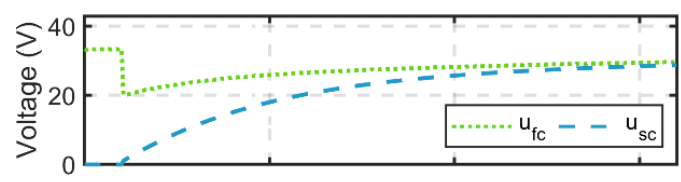

b)

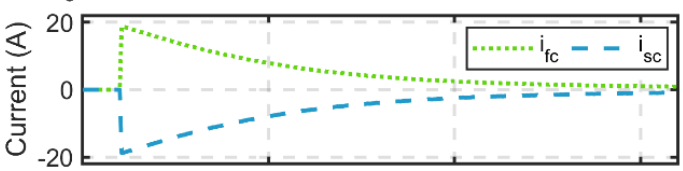

c)

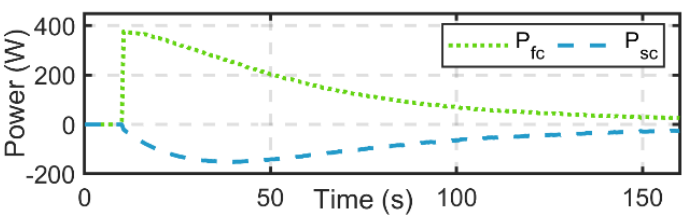

Fig. 12. Supercapacitors pre-charge, a) voltage profile, b) current profile, and c) power profile

\subsection{On-Road Operation}

The $1.2 \mathrm{~kW}$ programmable load reproduces the on-road power profile with a scale reduction of 25 . And the studied hybrid power source is based on a Horizon 500-W FC (H-500 FC) connected in parallel with a SC pack. Based on the proposed three-criteria sizing method the selected capacitor value is a pack of two 16.2 V-58F SC (BMOD0058 Maxwell SC) connected in series. This passive configuration avoids using a power electronics converter, because the current distribution between the FC and the SC depends on the natural behavior of each component. The experimental results of implemented $\mathrm{FC} / \mathrm{SC}$ passive coupling in real-time conditions; power, voltage, and current splits; are shown in Fig. 13. As with the hybrid source design validation test, the SCs are charged at $t=0 \mathrm{~s}$. It is observed from Fig. 13a that the traction power profile has two main peaks that overpass the maximum power of the FC. However, the SC has enough energy to immediately supply the requested power without a high voltage drop as shown in the storage capacity criterion. In this respect the Fig. 13b shows the SOC evolution of the SC. The lowest SOC is $89 \%$ that happens during the highest current peak of $30 \mathrm{~A}$. The FC voltage evolution operates in the linear zone of the polarization curve as shown in Fig. 13c, that avoids physical instability on the FC. In addition, the SC voltage never exceeds its voltage limits. Also, the FC current distribution is filtered thru the SC avoiding high current stress by the FC, as shown in Fig. 13d. The maximum current change per second is $1.2 \mathrm{~A} / \mathrm{s}$, which is inferior to the $2 \mathrm{~A} / \mathrm{s}$ design limit. As described, the $\mathrm{FC} / \mathrm{SC}$ passive system respects the all the sizing constraints, and the SCs assist the FC to meet the requirements of the load with a guarantee of system stability in real-time. 


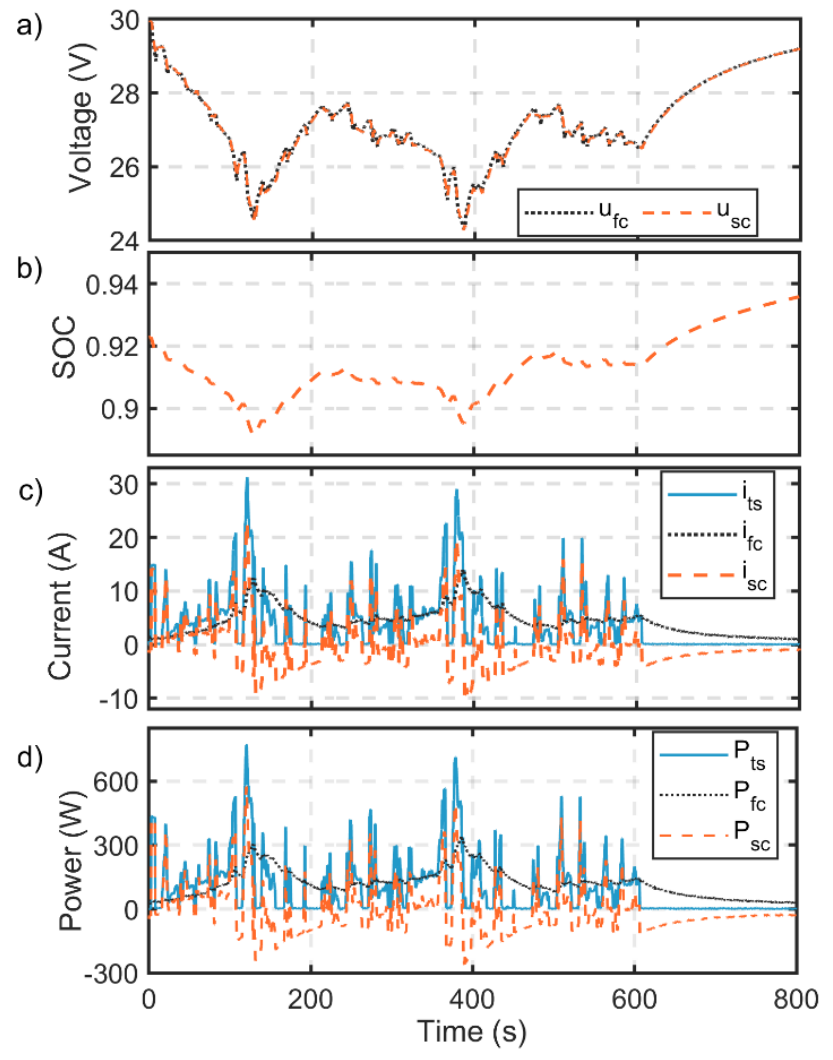

Fig. 13. Reduced-scale vehicle operation validation, measured signals a) voltage, b) SC SOC, c) current, and d) power

\section{Conclusion}

This paper deals with the design of a passive FC/SC hybrid source based on a three-criteria sizing method. As other sizing method found in the literature, storage capacity and voltage of the SC must be checked for security and efficiency purposes. The additional design criterion is the $\mathrm{FC}$ current dynamic, defined in a heuristic way to limit the FC degradation by limiting the FC current slope. For the SC design, the FC current versus the traction system current transfer function is defined based on the Mason's gain. Assuming that the used models are linear, the FC model, the analysis of this transfer function allows selecting the SC according to the desired FC operating frequency.

The proposed sizing approach allows to 1 ) reduce the FC degradation rate because the current slope, OCV, and stop-start operation are limited, and 2) improve the system efficiency because the SCs operate at a voltage discharge ratio upper than $50 \%$. The developed design method is validated in real-time on an experimental setup. Three tests are carried out: SC pre-charging, traction current step, and on-road operation. Experimental results have shown that the $\mathrm{SC}$ can assist the FC to meet the power requirements with a guarantee of system stability and design constrains.

In future, new strategies could be put forward to choose the optimal FC frequency operation, based on degradation, performance, or efficiency criteria. Additional work is required to model the FC degradations under a dynamic profile as presented in automotive application. Moreover, the study of a passive/active configuration, which uses an additional converter to convert the power from the SC to the traction, can be explored. This configuration could allow to start the vehicle without finishing the pre-charging phase but requires studying the minimum SC voltage to switch on the converter.

\section{Acknowledgment}

This work was supported by the Canada Research Chairs Program (grants 950-230863 and 950-230672 ), the National Sciences and Engineering Research Council of Canada (grants RGPIN-2018-06527 and RGPIN-201705924), the Emerging Leaders in the Americas Program (ELAP) and also with the support of the "Service de Coopération et d'Action Culturelle du Consulat Général de France à Québec" within the Samuel-De Champlain Program. 


\section{Nomenclatures}

$C_{s c}$

$E_{u}$

$f_{c}$

$i_{f c}$

$i_{s c}$

$I_{t s}$

$K_{f c}$

$K_{\text {load }}$

$K_{R}$

$K_{s c}$

$L_{i}$

$P_{F C, \max }$

$P_{L F}$

$P_{\text {load,max }}$

$P_{n}$

$P_{t s}$

$r_{D}$

$r_{s c}$

$T(s)$

$u_{f c}$

$u_{s c}$

$\Delta$

$\xi$

$\tau$

$\omega_{n}$

$R$

$k$

Equivalent capacitance of SC [F]

$\mathrm{SC}$ energy [J]

Cut-off frequency $[\mathrm{Hz}]$

FC current [A]

SC current [A]

Traction current [A]

FC switch

Load switch

Pre-charged switch

SC switch

Loop gain

Maximum FC power [W]

Low frequency power $[\mathrm{W}]$

Maximum load power [W]

Path cofactor

Traction power [W]

Equivalent diode resistance $[\Omega]$

Equivalent resistance of SC $[\Omega]$

Linear transfer function

$\mathrm{FC}$ voltage $[\mathrm{V}]$

SC voltage [V]

Determinant

Damping coefficient

Time constant [s]

Natural pulsation

Fixed resistor $[\Omega]$

Linear FC coefficient

Abbreviations and acronyms

DOE United States Department of Energy

FC Fuel cell

FC/SC Fuel cell/supercapacitor

GPS Global positioning system

H-500 FC Horizon 500-W FC

OCV Open circuit voltage

SC Supercapacitor

UQTR Université du Québec à Trois-Rivières

VSS Voltage Stabilization System

\section{References}

[1] G. Glenk and S. Reichelstein, "Economics of converting renewable power to hydrogen," Nature Energy, vol. 4, pp. $216-222,2019 / 03 / 01$ 2019.

[2] Z. Li, A. Khajepour, and J. Song, "A comprehensive review of the key technologies for pure electric vehicles," Energy, vol. 182, pp. 824-839, 2019/09/01/2019.

[3] G. Morrison, J. Stevens, and F. Joseck, "Relative economic competitiveness of light-duty battery electric and fuel cell electric vehicles," Transportation Research Part C: Emerging Technologies, vol. 87, pp. 183-196, 2018/02/01/2018.

[4] C. Acar and I. Dincer, "The potential role of hydrogen as a sustainable transportation fuel to combat global warming," International Journal of Hydrogen Energy, 2018/11/23/2018.

[5] M. Bodner, A. Schenk, D. Salaberger, M. Rami, C. Hochenauer, and V. Hacker, "Air Starvation Induced Degradation in Polymer Electrolyte Fuel Cells," Fuel Cells, vol. 17, pp. 18-26, 2017.

[6] F. X. Chen, Y. Yu, and J. X. Chen, "Control System Design of Power Tracking for PEM Fuel Cell Automotive Application," Fuel Cells, vol. 17, pp. 671-681, 2017.

[7] F. Nadeem, S. M. S. Hussain, P. K. Tiwari, A. K. Goswami, and T. S. Ustun, "Comparative Review of Energy Storage Systems, Their Roles, and Impacts on Future Power Systems," IEEE Access, vol. 7, pp. 4555-4585, 2019. 
B. Bendjedia, N. Rizoug, M. Boukhnifer, F. Bouchafaa, and M. Benbouzid, "Influence of secondary source technologies and energy management strategies on Energy Storage System sizing for fuel cell electric vehicles," International Journal of Hydrogen Energy, vol. 43, pp. 11614-11628, 2018/06/21/2018.

[9] H. S. Das, C. W. Tan, and A. H. M. Yatim, "Fuel cell hybrid electric vehicles: A review on power conditioning units and topologies," Renewable and Sustainable Energy Reviews, vol. 76, pp. 268-291, 2017.

[10] R. Á. Fernández, F. B. Cilleruelo, and I. V. Martínez, "A new approach to battery powered electric vehicles: A hydrogen fuel-cell-based range extender system," International Journal of Hydrogen Energy, vol. 41, pp. 4808-4819, 2016/03/02/ 2016.

[11] H. Wang, A. Gaillard, and D. Hissel, "A review of DC/DC converter-based electrochemical impedance spectroscopy for fuel cell electric vehicles," Renewable Energy, vol. 141, pp. 124-138, 2019/10/01/2019.

[12] M. J. Blackwelder and R. A. Dougal, "Power coordination in a fuel cell-battery hybrid power source using commercial power controller circuits," Journal of Power Sources, vol. 134, pp. 139-147, 2004/07/12/2004.

[13] A. Djerioui, A. Houari, S. Zeghlache, A. Saim, M. F. Benkhoris, T. Mesbahi, et al., "Energy management strategy of Supercapacitor/Fuel Cell energy storage devices for vehicle applications," International Journal of Hydrogen Energy, 2019/07/31/ 2019.

[14] M. Yue, S. Jemei, R. Gouriveau, and N. Zerhouni, "Review on health-conscious energy management strategies for fuel cell hybrid electric vehicles: Degradation models and strategies," International Journal of Hydrogen Energy, 2019/02/18/2019.

[15] M. S. Perdigão, J. P. F. Trovão, J. M. Alonso, and E. S. Saraiva, "Large-Signal Characterization of Power Inductors in EV Bidirectional DC-DC Converters Focused on Core Size Optimization," IEEE Transactions on Industrial Electronics, vol. 62, pp. 3042-3051, 2015.

[16] J. Bernard, M. Hofer, U. Hannesen, A. Toth, A. Tsukada, F. N. Büchi, et al., "Fuel cell/battery passive hybrid power source for electric powertrains," Journal of Power Sources, vol. 196, pp. 5867-5872, 2011/07/15/2011.

[17] H. Zhao and A. F. Burke, "Fuel Cell Powered Vehicles Using Supercapacitors-Device Characteristics, Control Strategies, and Simulation Results," Fuel Cells, vol. 10, pp. 879-896, 2010.

[18] D. Arora, C. Bonnet, M. Mukherjee, S. Raël, and F. Lapicque, "Direct hybridization of PEMFC and supercapacitors: Effect of excess hydrogen on a single cell fuel cell durability and its feasibility on fuel cell stack," Electrochimica Acta, vol. 310, pp. 213-220, 2019/07/01/2019.

[19] Q. Xun, Y. Liu, and E. Holmberg, "A Comparative Study of Fuel Cell Electric Vehicles Hybridization with Battery or Supercapacitor," in 2018 International Symposium on Power Electronics, Electrical Drives, Automation and Motion (SPEEDAM), 2018, pp. 389-394.

[20] A. Macías, M. Kandidayeni, L. Boulon, and J. Trovão, "Passive and Active Coupling Comparison of Fuel Cell and Supercapacitor for a ThreeWheel Electric Vehicle," Fuel Cells, vol. n/a, 2019/10/29 2019.

[21] K. Gérardin, S. Raël, C. Bonnet, D. Arora, and F. Lapicque, "Direct Coupling of PEM Fuel Cell to Supercapacitors for Higher Durability and Better Energy Management," Fuel Cells, vol. 18, pp. 315-325, 2018.

[22] B. Wu, M. A. Parkes, V. Yufit, L. De Benedetti, S. Veismann, C. Wirsching, et al., "Design and testing of a $9.5 \mathrm{kWe}$ proton exchange membrane fuel cell-supercapacitor passive hybrid system," International Journal of Hydrogen Energy, vol. 39, pp. 7885-7896, 2014.

[23] C. Turpin, D. Van Laethem, B. Morin, O. Rallières, X. Roboam, O. Verdu, et al., "Modelling and analysis of an original direct hybridization of fuel cells and ultracapacitors," Mathematics and Computers in Simulation, vol. 131, pp. 76-87, 2017.

[24] B. Morin, D. Van Laethem, C. Turpin, O. Rallières, S. Astier, A. Jaafar, et al., "Direct Hybridization Fuel Cell - Ultracapacitors," Fuel Cells, vol. 14 , pp. 500-507, 2014.

[25] C. Dépature, W. Lhomme, P. Sicard, A. Bouscayrol, and L. Boulon, "Real-Time Backstepping Control for Fuel Cell Vehicle Using Supercapacitors," IEEE Transactions on Vehicular Technology, vol. 67, pp. 306-314, 2018.

[26] M. Kaus, J. Kowal, and D. U. Sauer, "Modelling the effects of charge redistribution during self-discharge of supercapacitors," Electrochimica Acta, vol. 55, pp. 7516-7523, 2010/10/30/ 2010.

[27] M. Hinaje, S. Raël, J. P. Caron, and B. Davat, "An innovating application of PEM fuel cell: Current source controlled by hydrogen supply," International Journal of Hydrogen Energy, vol. 37, pp. 12481-12488, 2012/09/01/2012.

[28] R. E. Silva, F. Harel, S. Jemeï, R. Gouriveau, D. Hissel, L. Boulon, et al., "Proton Exchange Membrane Fuel Cell Operation and Degradation in Short-Circuit," Fuel Cells, vol. 14, pp. 894-905, 2014.

[29] D. Arora, M. Hinaje, C. Bonnet, S. Raeel, and F. Lapicque, "Sizing Supercapacitor for Direct Hybridization with Polymer Electrolyte Membrane Fuel Cell," in 2018 IEEE Vehicle Power and Propulsion Conference (VPPC), 2018, pp. 1-7.

[30] D. B. W. Abeywardana, B. Hredzak, V. G. Agelidis, and G. D. Demetriades, "Supercapacitor Sizing Method for Energy-Controlled Filter-Based Hybrid Energy Storage Systems," IEEE Transactions on Power Electronics, vol. 32, pp. 1626-1637, 2017.

[31] F. Martel, S. Kelouwani, Y. Dubé, and K. Agbossou, "Optimal economy-based battery degradation management dynamics for fuel-cell plug-in hybrid electric vehicles," Journal of Power Sources, vol. 274, pp. 367-381, 2015/01/15/2015.

[32] S. Kelouwani, K. Agbossou, Y. Dubé, and L. Boulon, "Energetic Optimization of the Driving Speed Based on Geographic Information System Data," in 2012 IEEE Vehicular Technology Conference (VTC Fall), 2012, pp. 1-5.

[33] J. Snoussi, S. B. Elghali, M. Benbouzid, and M. F. Mimouni, "Optimal Sizing of Energy Storage Systems Using Frequency-Separation-Based Energy Management for Fuel Cell Hybrid Electric Vehicles," IEEE Transactions on Vehicular Technology, vol. 67, pp. 9337-9346, 2018.

[34] C. Bonnet, F. Lapicque, M. Belhadj, K. Gerardin, S. Raël, M. Hinaje, et al., "Can PEM Fuel Cells Experience Appreciable Degradation at Short Circuit?," Fuel Cells, vol. 17, pp. 157-165, 2017/04/01 2017.

[35] Nissan, "Fuel cell system," 2005.

[36] N. Marx, D. Hissel, D. C. Toquica Cárdenas, L. Boulon, and F. Gustin, "Degraded mode operation of multi-stack fuel cell systems," IET Electrical Systems in Transportation, vol. 6, pp. 3-11, 2016.

[37] A. Saadi, M. Becherif, D. Hissel, and H. S. Ramadan, "Dynamic modeling and experimental analysis of PEMFCs: A comparative study," International Journal of Hydrogen Energy, vol. 42, pp. 1544-1557, 2017/01/12/ 2017.

[38] M. Kandidayeni, A. Macias, A. A. Amamou, L. Boulon, S. Kelouwani, and H. Chaoui, "Overview and benchmark analysis of fuel cell parameters estimation for energy management purposes," Journal of Power Sources, vol. 380, pp. 92-104, 2018.

[39] L. Zubieta and R. Bonert, "Characterization of double-layer capacitors for power electronics applications," IEEE Transactions on Industry Applications, vol. 36, pp. 199-205, 2000.

[40] A. Bouscayrol, J.-P. Hautier, and B. Lemaire-Semail, "Graphic Formalisms for the Control of Multi-Physical Energetic Systems: COG and EMR," in Systemic Design Methodologies for Electrical Energy Systems, I. a. Wiley, Ed., ed, 2012, pp. 89-124.

[41] H. Marzougui, A. Kadri, M. Amari, and F. Bacha, "Energy Management of Fuel Cell Vehicle with Hybrid Storage System: A Frequency Based Distribution," in 2019 6th International Conference on Control, Decision and Information Technologies (CoDIT), 2019, pp. 1853-1858.

[42] W. Wu, J. S. Partridge, and R. W. G. Bucknall, "Stabilised control strategy for PEM fuel cell and supercapacitor propulsion system for a city bus," International Journal of Hydrogen Energy, vol. 43, pp. 12302-12313, 2018.

[43] H. Chen, S. Xu, P. Pei, B. Qu, and T. Zhang, "Mechanism analysis of starvation in PEMFC based on external characteristics," International Journal of Hydrogen Energy, vol. 44, pp. 5437-5446, 2019.

[44] M. G. Carignano, R. Costa-Castelló, V. Roda, N. M. Nigro, S. Junco, and D. Feroldi, "Energy management strategy for fuel cell-supercapacitor hybrid vehicles based on prediction of energy demand," Journal of Power Sources, vol. 360, pp. 419-433, 2017/08/31/2017. 
[45] Y. Wang, S. J. Moura, S. G. Advani, and A. K. Prasad, "Power management system for a fuel cell/battery hybrid vehicle incorporating fuel cell and battery degradation," International Journal of Hydrogen Energy, vol. 44, pp. 8479-8492, 2019/03/29/2019.

[46] P. Pei, Q. Chang, and T. Tang, "A quick evaluating method for automotive fuel cell lifetime," International Journal of Hydrogen Energy, vol. 33, pp. 3829-3836, 2008/07/01/2008.

[47] G. Wang, F. Huang, Y. Yu, S. Wen, and Z. Tu, "Degradation behavior of a proton exchange membrane fuel cell stack under dynamic cycles between idling and rated condition," International Journal of Hydrogen Energy, vol. 43, pp. 4471-4481, 2018/03/01/ 2018.

[48] M. Chandesris, R. Vincent, L. Guetaz, J. S. Roch, D. Thoby, and M. Quinaud, "Membrane degradation in PEM fuel cells: From experimental results to semi-empirical degradation laws," International Journal of Hydrogen Energy, vol. 42, pp. 8139-8149, 2017/03/23/ 2017.

[49] L. An, T. Zhao, X. Yan, X. Zhou, and P. Tan, "The dual role of hydrogen peroxide in fuel cells," Science Bulletin, vol. 60, pp. 55-64, 2015/01/01 2015.

[50] U. Drive, "Target explanation document: onboard hydrogen storage for light-duty fuel cell vehicles," Department of Energy2015.

[51] B. Bendjedia, F. Bouchafaa, N. Rizoug, and M. Boukhnifer, "Comparative study between battery and supercapacitor hybridization with fuel cells for automotive applications," in 2017 4th International Conference on Control, Decision and Information Technologies (CoDIT), 2017, pp. 08330838 .

[52] L. Zhang, X. Hu, Z. Wang, F. Sun, and D. G. Dorrell, "A review of supercapacitor modeling, estimation, and applications: A control/management perspective," Renewable and Sustainable Energy Reviews, vol. 81, pp. 1868-1878, 2018.

[53] T. Li, H. Liu, D. Zhao, and L. Wang, "Design and analysis of a fuel cell supercapacitor hybrid construction vehicle," International Journal of Hydrogen Energy, vol. 41, pp. 12307-12319, 2016/07/27/ 2016.

[54] K. Ogata and Y. Yang, "Mathematical modeling of dynamic systems," in Modern control engineering. vol. 17, ed: Pearson Upper Saddle River, NJ, 2010, pp. 57-129.

[55] H. Abdi, R. Rasouli Nezhad, and M. Salehimaleh, "Chapter 5 - Fuel Cells," in Distributed Generation Systems, G. B. Gharehpetian and S. M. Mousavi Agah, Eds., ed: Butterworth-Heinemann, 2017, pp. 221-300.

[56] R. Zhang and J. Tao, "GA-Based Fuzzy Energy Management System for FC/SC-Powered HEV Considering H2Consumption and Load Variation," IEEE Transactions on Fuzzy Systems, vol. 26, pp. 1833-1843, 2018.

[57] G. Chiappori, P. L. Moigne, P. Delarue, and M. Chemin, "Voltage Stabilization System for Stop - Start Vehicles: Systemic Approach," in 2014 IEEE Vehicle Power and Propulsion Conference (VPPC), 2014, pp. 1-6.

[58] Y. Wang, J. Chen, J. Liu, K. Liu, Y. Zhang, J. Wu, et al., "Research and implementation of key technology of braking energy recovery system for off-highway dump truck," in IECON 2017 - 43rd Annual Conference of the IEEE Industrial Electronics Society, 2017, pp. 3912-3917. 